\title{
Fall-related injuries among Canadian seniors, 2005-2013: an analysis of the Canadian Community Health Survey
}

\author{
M. T. Do, PhD (1); V. C. Chang, MPH (2); N. Kuran, MA (3); W. Thompson, MSc (1)
}

This article has been peer reviewed.

Tweet this article

\section{Abstract}

Introduction: We describe the epidemiology and trends of fall-related injuries among Canadian seniors aged 65 years and older by sex and age, as well as the circumstances and consequences of their injuries.

Methods: We analyzed nationally representative data from the 2005, 2009/2010 and 2013 samples of the Canadian Community Health Survey to calculate the number and rates of fall-related injuries for each survey year. Where possible, we combined data from two or more samples to estimate the proportion of fall-related injuries by type of injury, part of body injured, type of activity and type of treatment.

Results: The rate of fall-related injuries among seniors increased from 49.4 to 58.8 per 1000 population between 2005 and 2013, during which the number of fall-related injuries increased by $54 \%$ overall. Women had consistently higher rates than men across all survey years, while rates increased with advancing age. The upward trend in fall-related injury rates was more prominent among women and younger age groups. The most common type of injury was broken or fractured bones (37\%), and the shoulder or upper arm (16\%) was the most commonly injured body part. Many fall-related injuries occurred while walking on a surface other than snow or ice $(45 \%)$. Over $70 \%$ of seniors seeking treatment for their injuries visited a hospital emergency department.

Conclusion: Given the increase in both the number and rates of fall-related injuries over time, there is a need to continue monitoring trends and injury patterns associated with falls.

Keywords: falls, unintentional injuries, seniors, Canada

\section{Introduction}

Each year, about one in three seniors experience at least one fall. ${ }^{1-5}$ In $2008-$ 2009, $20 \%$ of Canadians aged 65 years or older who were living in the community reported falling in the previous year. ${ }^{6}$ This prevalence increased with age, from $17 \%$ among those aged 65 to 69 years to $27 \%$ among those aged 85 years or older. ${ }^{6}$

Falls are also the leading cause of injuryrelated hospitalizations among Canadian seniors. ${ }^{7}$ They result in an average length of hospital stay of approximately 3 weeks, which is $75 \%$ longer than the average length of stay for all causes of hospitalization combined. ${ }^{7}$ Fall-related injuries are associated with significant disability, reduced mobility and independence, higher likelihood of admission to a nursing home and increased risk of premature death. ${ }^{8,9}$ Falls are responsible for $95 \%$ of hip fractures in older adults, ${ }^{10}$ leading to death in more than $20 \%$ of cases. ${ }^{11}$

Even in the absence of injuries, falls may have long-term psychological consequences,
Key findings

- Between 2005 and 2013, the rate of fall-related injuries among Canadian seniors aged 65 years or older increased from 49.4 to 58.8 per 1000 population.

- Fall-related injuries are more common in women and in older age groups.

- A significant increase in the rate of fall-related injury between 2005 and 2013 was observed in women and in those aged less than 75 years.

- Fractures accounted for $37 \%$ of all injuries due to falls, highlighting the importance of bone health.

- More years of survey data are needed to assess longer-term trends of fallrelated injuries among seniors.

such as depression, fear of falling and loss of confidence. These, in turn, lead to restriction in daily and social activities and, subsequently, declines in health and function and increased risk of future falls. ${ }^{12-14}$

In addition to increased morbidity and mortality, fall-related injuries pose an economic burden on the health care system. ${ }^{15-18}$ In Canada, direct medical costs associated with falls among seniors were estimated at over $\$ 2$ billion in 2004. ${ }^{19}$ This figure is expected to rise substantially as the number of Canadians aged 65 years or older is projected to more than double, from 5 million $(15 \%)$ in $2011^{20}$ to nearly 11 million $(25 \%)$ in $2036 .^{21}$

In April 2014, the Public Health Agency of Canada released its second report on falls among seniors. ${ }^{7}$ The report provided an

Author references:

1. Surveillance and Epidemiology Division, Public Health Agency of Canada, Ottawa, Ontario, Canada

2. Dalla Lana School of Public Health, University of Toronto, Toronto, Ontario, Canada

3. Seniors Policy Unit, Division of Children, Seniors, and Healthy Development, Public Health Agency of Canada, Ottawa, Ontario, Canada

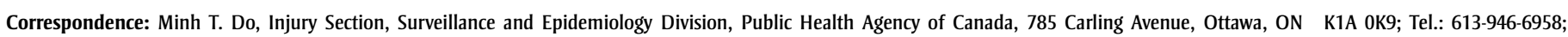
Fax: 613-941-2057; Email: minh.t.do@phac-aspc.gc.ca 
overview of risk factors for falls and presented national estimates of fall-related injuries derived from survey, hospitalization and mortality data. Specifically, data from the Canadian Community Health Survey (CCHS) showed that the number of seniors self-reporting injuries due to falls increased from about 179000 to 256000 (43\%) between 2003 and 2009/ $2010 .^{7}$ In addition, the rate of fall-related injuries was significantly higher in women than men across all survey years. ${ }^{7}$ With data newly available from the 2013 CCHS, an updated analysis is warranted to describe the current state of fall-related injuries among Canadian seniors.

This study aims to (1) provide the most recent national estimates of the number and rates of self-reported fall-related injuries by sex and age and estimate trends between 2005 and 2013, (2) compare the distribution of key demographic characteristics between seniors with and without a fall-related injury, and (3) describe injury characteristics associated with falls, including the nature and circumstances of injury, as well as health care utilization following a fall-related injury.

\section{Methods}

\section{Data source}

We used nationally representative data from the CCHS for the years 2005, 2009/ 2010 (combined) and 2013. The CCHS is a cross-sectional survey that collects information on the health status, health care utilization and health determinants of the Canadian population. Using a multistage stratified design, the CCHS targeted individuals aged 12 years and older living in private dwellings across the 10 provinces and 3 territories of Canada. People living on Indian reserves or Crown lands, residents of institutions, full-time members of the Canadian Forces and residents of certain remote regions were excluded. Three sampling frames were used to select the sample of households, with $99 \%$ coming from an area frame or a list frame of telephone numbers and the remaining $1 \%$ from a random digit-dialling frame. All surveys were conducted using computer-assisted personal or telephone interviewing. The response rates for the 2005, 2009/2010 and 2013 CCHS were $78.9 \%, 72.3 \%$ and $66.8 \%$, respectively. Since 2007 , instead of a 1-year collection period with data released every 2 years, CCHS data have been collected continually and released annually (or biannually as a 2-year data file).

Our analyses did not include data from the $2007 / 2008$ and 2011/2012 surveys as information on injuries was collected only in certain provinces or territories in those years (British Columbia and Nova Scotia in 2007/2008; Alberta and Northwest Territories in 2011/2012). Moreover, since data from the 2014 CCHS were still being collected at the time of our analyses, the most recent estimates were derived from the annual data file of 2013, which consisted of a smaller sample compared to the 2005 and $2009 / 2010$ samples. A detailed description of the CCHS, including background and methodology, can be found elsewhere. ${ }^{22-24}$

We obtained study samples from the CCHS share files that contain records of all respondents who agreed to share their data with the Public Health Agency of Canada. This represented approximately $95 \%$ of the full sample for each survey year. Very small differences in the distribution of variables were observed between the share file and the master file containing the full CCHS sample. ${ }^{24}$ For the purpose of this study, the samples were restricted to respondents aged 65 years or older ( $\mathrm{n}=26188$ in 2005; $\mathrm{n}=28379$ in 2009/2010; $n=17290$ in 2013).

\section{Fall-related injury}

The Injuries module of the CCHS included a question that asked respondents if they had sustained an injury serious enough to limit their normal activities (e.g. a broken bone, a bad cut, a burn or a sprain) in the previous year. Those who answered "yes" to the question "In the past 12 months, were you injured?" were asked about their most serious injury, including whether that injury was a result of a fall. Those who responded "yes" were identified as having a fall-related injury. Information on the type of injury, the part of the body injured, the type of activity associated with the fall and the type of treatment received within 48 hours of injury was collected using questions with a predefined list of responses.

\section{Demographic characteristics}

The demographic characteristics examined included

- sex;

- age $(65-69,70-74,75-79,80-84,85-$ 89 , and $\geq 90$ years);

- marital status (married/common-law, widowed, separated/divorced, and single/never married);

- highest level of education attained (less than secondary school graduation, secondary school graduation, some postsecondary, and post-secondary graduation) and

- household income $(<\$ 15$ 000, \$15 000-\$29 999, \$30 000-\$49 999, \$50 000-\$79 999, and $\geq \$ 80$ 000).

For ease of comparison, these variables were categorized according to the Public Health Agency of Canada's report. ${ }^{7}$ Respondents with missing data (i.e. unknown or refused to answer) on each variable were included as a separate category, with the exception of household income, for which missing data ( 20\%) were imputed by Statistics Canada using a nearest neighbour imputation method. ${ }^{25}$

\section{Statistical analyses}

We used descriptive statistics to examine the distribution of demographic characteristics by fall-related injury status in each survey sample. The Rao-Scott chisquare test, which is the equivalent of a Pearson chi-square test adjusted for design effects of the survey, ${ }^{26}$ was used to test differences in the distribution of characteristics between seniors with and without a fall-related injury. The frequency and prevalence rate (number of people reporting an injury due to a fall during the previous year, per 1000 population) of fall-related injuries were also determined for each survey sample, with further stratification by sex and age group. To examine trends over time, we 
used z-tests to assess differences in rates between successive survey samples, as well as between the 2005 and 2013 samples. All tests were two-sided, and a $p$ value of $<.05$ was considered statistically significant. Due to small numbers in some categories, data from at least two of the three survey samples were combined $^{27}$ to calculate the proportion of fall-related injuries by type of injury, part of body injured, type of activity, and type of treatment.
To account for the complex sampling design of the CCHS (e.g. adjustments for non-response, under-coverage and poststratification) and to obtain estimates representative of the Canadian population, we used sampling weights in all the

TABLE 1

Demographic characteristics of seniors, $\geq 65$ years, by fall-related injury status, Canada, CCHS 2005, 2009/2010, 2013

\begin{tabular}{|c|c|c|c|c|c|c|c|c|c|c|c|c|}
\hline \multirow[t]{3}{*}{ Characteristics } & \multicolumn{4}{|c|}{ CCHS 2005} & \multicolumn{4}{|c|}{ CCHS 2009/2010 } & \multicolumn{4}{|c|}{ CCHS 2013} \\
\hline & \multicolumn{2}{|c|}{$\begin{array}{l}\text { Without a fall- } \\
\text { related Injury }\end{array}$} & \multicolumn{2}{|c|}{$\begin{array}{l}\text { With a fall- } \\
\text { related Injury }\end{array}$} & \multicolumn{2}{|c|}{$\begin{array}{l}\text { Without a fall- } \\
\text { related Injury }\end{array}$} & \multicolumn{2}{|c|}{$\begin{array}{l}\text { With a fall- } \\
\text { related Injury }\end{array}$} & \multicolumn{2}{|c|}{$\begin{array}{l}\text { Without a fall- } \\
\text { related Injury }\end{array}$} & \multicolumn{2}{|c|}{$\begin{array}{l}\text { With a fall- } \\
\text { related Injury }\end{array}$} \\
\hline & $\mathbf{n}$ & $\%$ & $\mathbf{n}$ & $\%$ & $\mathbf{n}$ & $\%$ & $\mathbf{n}$ & $\%$ & $\mathbf{n}$ & $\%$ & $\mathbf{n}$ & $\%$ \\
\hline Total sample (unweighted) & 24809 & & 1379 & & 26743 & & 1636 & & 16303 & & 987 & \\
\hline Total population (weighted) & 3734171 & & 194135 & & 4198003 & & 256011 & & 4797658 & & 299769 & \\
\hline \multicolumn{13}{|l|}{$\operatorname{Sex}^{*}$} \\
\hline Male & 1686873 & 45.2 & 61034 & 31.4 & 1918788 & 45.7 & 93090 & 36.4 & 2231422 & 46.5 & 99435 & 33.2 \\
\hline Female & 2047298 & 54.8 & 133102 & 68.6 & 2279215 & 54.3 & 162921 & 63.6 & 2566236 & 53.5 & 200334 & 66.8 \\
\hline \multicolumn{13}{|l|}{ Age, years* } \\
\hline $65-69$ & 1162501 & 31.1 & 49181 & 25.3 & 1415712 & 33.7 & 74185 & 29.0 & 1672895 & 34.9 & 98187 & 32.8 \\
\hline $70-74$ & 987761 & 26.5 & 41277 & 21.3 & 1005525 & 24.0 & 47348 & 18.5 & 1165446 & 24.3 & 68557 & 22.9 \\
\hline $75-79$ & 768719 & 20.6 & 46186 & 23.8 & 841906 & 20.1 & 55126 & 21.5 & 907011 & 18.9 & 47693 & 15.9 \\
\hline $80-84$ & 519888 & 13.9 & 29353 & 15.1 & 570275 & 13.6 & 36653 & 14.3 & 613432 & 12.8 & 44021 & 14.7 \\
\hline $85-89$ & 225167 & 6.0 & 20099 & 10.4 & 273249 & 6.5 & 32484 & 12.7 & 320060 & 6.7 & 30437 & 10.2 \\
\hline$\geq 90$ & 70134 & 1.9 & 8040 & $4.1^{\mathrm{E}}$ & 91336 & 2.2 & 10215 & $4.0^{\mathrm{E}}$ & 118815 & 2.5 & 10874 & $3.6^{\mathrm{E}}$ \\
\hline \multicolumn{13}{|l|}{ Marital status* } \\
\hline Married/common-law & 2334287 & 62.5 & 100592 & 51.8 & 2670783 & 63.6 & 143006 & 55.9 & 3112314 & 64.9 & 160737 & 53.6 \\
\hline Widowed & 980197 & 26.2 & 69984 & 36.0 & 989597 & 23.6 & 79415 & 31.0 & 999912 & 20.8 & 82685 & 27.6 \\
\hline Separated/divorced & 240658 & 6.4 & 14570 & 7.5 & 342082 & 8.1 & 23245 & 9.1 & 446792 & 9.3 & 38582 & 12.9 \\
\hline Single, never married & 176653 & 4.7 & 8907 & 4.6 & 185020 & 4.4 & 10344 & 4.0 & 232313 & 4.8 & 17766 & $5.9^{\mathrm{E}}$ \\
\hline Not stated ${ }^{\mathrm{a}}$ & 2376 & $0.1^{\mathrm{E}}$ & $x$ & $x$ & 10521 & $0.3^{\mathrm{E}}$ & 0 & 0.0 & $x$ & $x$ & 0 & 0.0 \\
\hline \multicolumn{13}{|l|}{ Education } \\
\hline$<$ Secondary school graduation & 1522865 & 40.8 & 76403 & 39.4 & 1433432 & 34.1 & 76714 & 30.0 & 1476635 & 30.8 & 89869 & 30.0 \\
\hline Secondary school graduation & 495206 & 13.3 & 28856 & 14.9 & 618242 & 14.7 & 41275 & 16.1 & 896124 & 18.7 & 53225 & 17.8 \\
\hline Some post-secondary & 186005 & 5.0 & 11481 & 5.9 & 227552 & 5.4 & 15901 & 6.2 & 158172 & 3.3 & 8962 & $3.0^{\mathrm{E}}$ \\
\hline Post-secondary graduation & 1395142 & 37.4 & 72526 & 37.4 & 1763707 & 42.0 & 112140 & 43.8 & 2152020 & 44.9 & 137858 & 46.0 \\
\hline Not stated ${ }^{\mathrm{a}}$ & 134952 & 3.6 & $x$ & $x$ & 155070 & 3.7 & 9981 & $3.9^{\mathrm{E}}$ & 114707 & 2.4 & 9855 & $3.3^{\mathrm{E}}$ \\
\hline \multicolumn{13}{|l|}{ Household income, $\$^{b}$} \\
\hline$<15000$ & 405814 & 10.9 & 28492 & 14.7 & 279721 & 6.7 & 19440 & 7.6 & 213042 & 4.4 & 18142 & $6.1^{\mathrm{E}}$ \\
\hline 15 000-29 999 & 1243428 & 33.3 & 60838 & 31.3 & 1114828 & 26.6 & 66769 & 26.1 & 1239972 & 25.8 & 82199 & 27.4 \\
\hline $30000-49999$ & 1031015 & 27.6 & 50514 & 26.0 & 1237856 & 29.5 & 74692 & 29.2 & 1310159 & 27.3 & 79782 & 26.6 \\
\hline 50 000-79 999 & 691384 & 18.5 & 34917 & 18.0 & 916035 & 21.8 & 55819 & 21.8 & 1109802 & 23.1 & 75191 & 25.1 \\
\hline$\geq 80000$ & 362531 & 9.7 & 19375 & 10.0 & 649564 & 15.5 & 39291 & 15.3 & 924683 & 19.3 & 44455 & 14.8 \\
\hline
\end{tabular}

Source: Canadian Community Health Survey (2005, 2009/2010, 2013), Statistics Canada.

Abbreviation: CCHS, Canadian Community Health Survey.

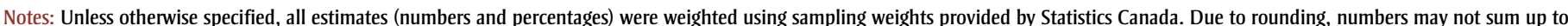
the total population and percentages may not sum up to $100 \%$.

a "Not stated" includes all responses categorized as "don't know," "refusal," or "not stated".

b Missing data on household income were imputed using a nearest neighbour imputation method. ${ }^{25}$

${ }^{E}$ Estimate is associated with high sampling variability (i.e. coefficient of variation is between $16.6 \%$ and $33.3 \%$ ) - interpret with caution.

" $x$ " indicates that the data do not meet standards for reportability due to extreme variability (coefficient of variation $>33.3 \%$ ).

* Significant difference $(p<.05)$ in the distribution of the characteristic between those with a fall-related injury and those without a fall-related injury for all 3 survey samples. 
analyses. ${ }^{24}$ Variance estimates, including $95 \%$ confidence intervals (CIs) and coefficients of variation (CVs), were calculated using the bootstrap technique and the BOOTVAR 3.2 program developed by Statistics Canada. ${ }^{28}$ The bootstrap technique involves a repeated process of selecting simple random samples $(\mathrm{n}=500)$ from the CCHS dataset, recalculating sampling weights for each selected subsample, and post-stratifying weights for each stratum to obtain the final bootstrap weights. $^{24,28}$ Estimates are reported according to Statistics Canada's sampling variability guidelines: ${ }^{24}$ those with a CV between $16.6 \%$ and $33.3 \%$ are flagged to be interpreted with caution due to high sampling variability, while those with a CV greater than $33.3 \%$ are not reported due to extreme variability.

All analyses were conducted using SAS version 9.3 (SAS Institute Inc., Cary, North Carolina, USA).

\section{Results}

The number of respondents aged 65 years or older in the 2005, 2009/2010 and 2013 CCHS samples were 26188,28379 and 17 290, respectively. This represented a total population of community-dwelling Canadian seniors of about 3.9 million in 2005 and 5.1 million in 2013.

Table 1 shows the distribution of demographic characteristics among respondents with or without a fall-related injury in each of the three CCHS samples. For all survey years, fall-related injury status in the previous 12 months differed by sex, age and marital status $(p<.05)$. Compared to those without a fall-related injury, seniors reporting a fall-related injury were more likely to be women, to be older and to be widowed and less likely to be married. We did not observe any statistically significant differences by education level or household income for any of the three samples.

\section{Rates and trends}

Figure 1 shows the estimated numbers and rates of fall-related injuries among Canadian seniors across all survey years. In 2005, 194135 Canadians aged 65 years or

\section{FIGURE 1}

Numbers and rates of fall-related injuries, $\geq 65$ years, Canada, CCHS 2005, 2009/2010, 2013

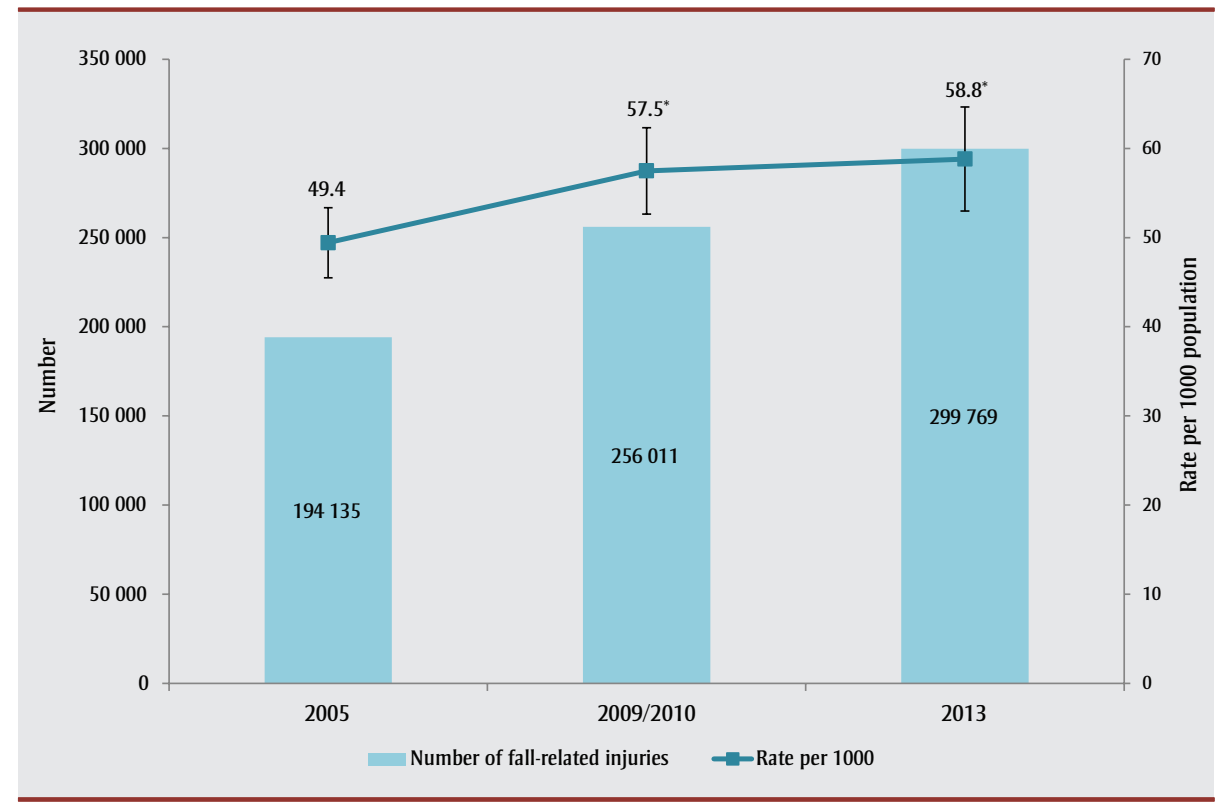

Source: Canadian Community Health Survey (2005, 2009/2010, 2013), Statistics Canada.

Abbreviation: CCHS, Canadian Community Health Survey.

Notes: Numbers and rates (per 1000 population) of fall-related injuries were calculated using sampling weights. Error bars represent $95 \%$ confidence intervals of rates of fall-related injuries, computed using the bootstrap technique.

* Significantly different from the 2005 estimate $(p<.05)$ based on the z-test for proportions.

older reported being injured due to a fall in the previous 12 months. This number increased to 256011 in 2009/2010 and 299769 in 2013, with an overall increase of $54 \%$ from 2005 to 2013 . A similar upward trend was observed in the rate of fallrelated injuries, from 49.4 (95\% CI: $45.5-$ 53.3) per 1000 population in 2005 to 57.5 (95\% CI: 52.6-62.3) per 1000 in 2009/2010 and 58.8 (95\% CI: 53.0-64.6) per 1000 in 2013. Compared to 2005, the rate estimate was significantly higher in 2013 ( $p=.01$ ). Of note, while the increase in rate between 2005 and 2009/2010 was statistically significant ( 8.1 per $1000, p=.01$ ), the rate appeared to level off, with only a small and non-significant increase between 2009/ 2010 and 2013 (1.3 per 1000, $p=.72$ ).

Figure 2 shows rates of fall-related injuries by sex and survey year. Based on nonoverlapping CIs, women had significantly higher rates of fall-related injuries than men across all survey years, with femaleto-male ratios ranging from 1.4 to 1.7. Fallrelated injury rates for women increased steadily from 61.0 (95\% CI: 55.2-66.9) per 1000 in 2005 to 72.4 (95\% CI: 63.9-80.9) per 1000 in 2013 ( $p=.03$ for 2013 vs.
2005). On the other hand, whereas men experienced a marked increase between 2005 and 2009/2010, from 34.9 (95\% CI: 30.2-39.6) per 1000 to 46.3 (95\% CI: 39.5-53.1) per 1000 ( $p=.007)$, there was a small but non-significant decrease between $2009 / 2010$ and 2013 , to a rate of 42.7 (95\% CI: 35.0-50.4) per 1000 in 2013. Unlike for women, the difference in rates between the 2005 and 2013 samples was not statistically significant for men $(p=.10)$.

Figure 3 shows rates of fall-related injuries by 5 -year age groups and survey year. In general, the rate of fall-related injuries increased with advancing age in all survey years, with a larger increase from the 8084 to the 85-89 age group. From 2005 to 2013, a significant upward trend was seen among those aged 65-69 and 70-74 years ( $p=.02$ for both), while a non-significant decline was noted in the oldest age group (i.e. $\geq 90$ years). Moreover, in 2005, the rate of fall-related injuries among seniors aged 90 years or older was 2.5 times that among those aged 65 to 69 years (102.8 vs. 40.6 per 1000$)$, but this ratio decreased to 2.0 in $2009 / 2010$ (100.6 vs. 
FIGURE 2

Rates of fall-related injuries by sex, $\geq 65$ years, Canada, CCHS 2005, 2009/2010, 2013

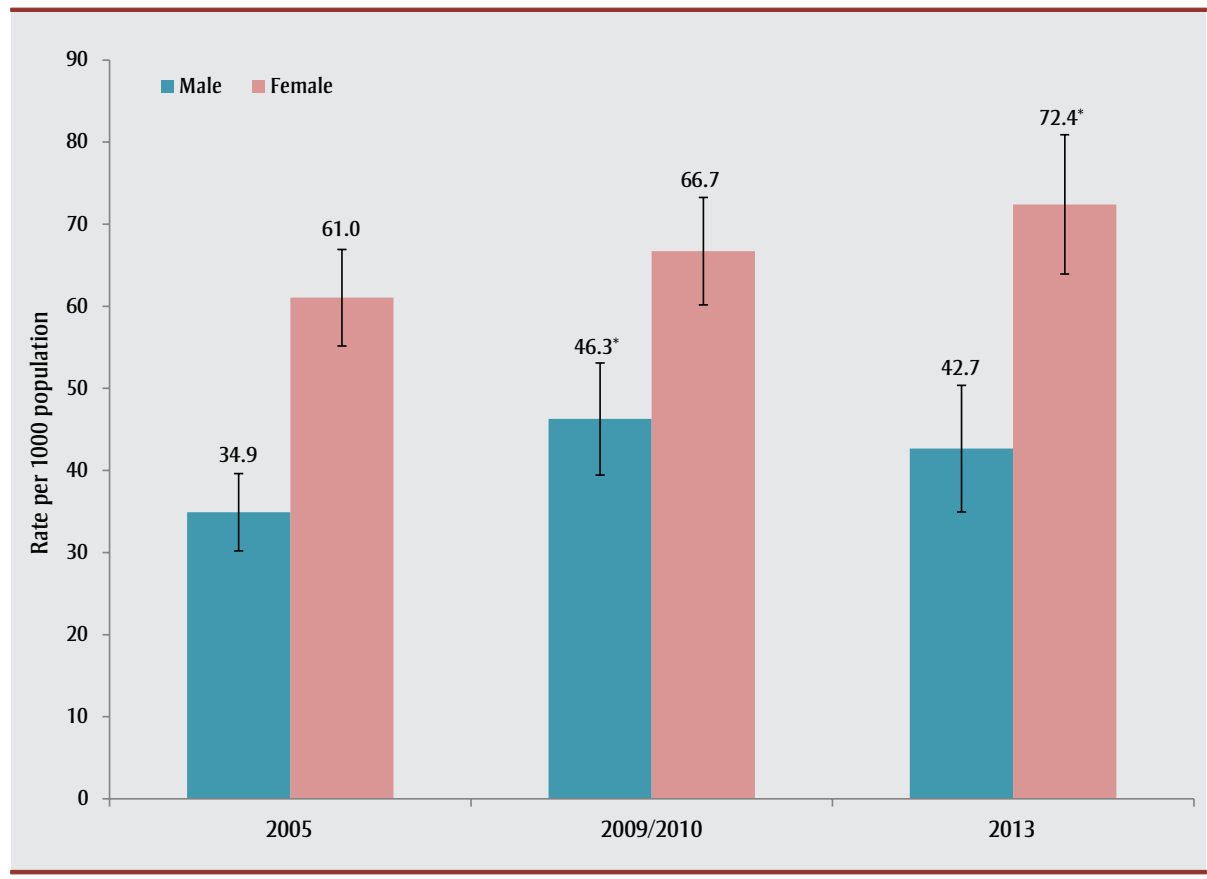

Source: Canadian Community Health Survey (2005, 2009/2010, 2013), Statistics Canada.

Abbreviation: CCHS, Canadian Community Health Survey.

Notes: Rates of fall-related injuries were calculated per 1000 population using sampling weights. Error bars represent $95 \%$ confidence intervals computed using the bootstrap technique.

* Significantly different from the 2005 estimate $(p<.05)$ based on the z-test for proportions.

FIGURE 3

Rates of fall-related injuries by age group, $\geq 65$ years, Canada, CCHS 2005, 2009/2010, 2013

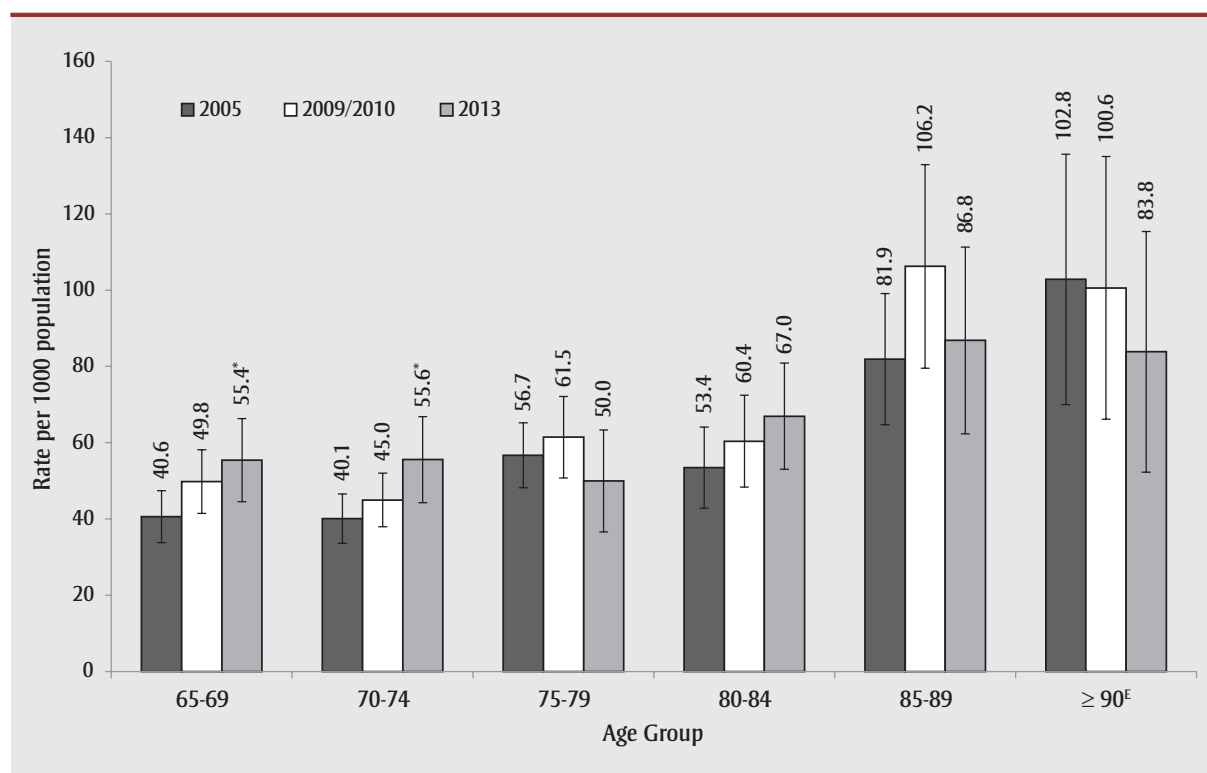

Source: Canadian Community Health Survey (2005, 2009/2010, 2013), Statistics Canada.

Abbreviation: CCHS, Canadian Community Health Survey.

Notes: Rates of fall-related injuries were calculated per 1000 population using sampling weights. Error bars represent 95\% confidence intervals computed using the bootstrap technique.

E Estimates for the 2009/2010 and 2013 samples are associated with high sampling variability (i.e. coefficient of variation is between $16.6 \%$ and $33.3 \%$ ) - interpret with caution.

* Significantly different from the 2005 estimate $(p<.05)$ based on the z-test for proportions.
49.8 per 1000) and 1.5 in 2013 (83.8 vs. 55.4 per 1000).

\section{Injury characteristics}

Based on combined data from the 2005, 2009/2010 and 2013 samples, Figures 4 and 5 show the proportion of fall-related injuries by type of injury and part of body injured, respectively. The majority of fallrelated injuries involved broken or fractured bones $(37 \%)$, sprains or strains $(27 \%)$ and scrapes, bruises or blisters $(17 \%)$. The body parts that were most frequently affected were shoulder or upper arm (16\%), knee or lower leg (13\%) and ankle or foot $(11 \%)$. Although the wording in the 2009/2010 and 2013 questionnaires changed slightly from that in 2005 (e.g. the "sprain or strain" category was given more details in 2009/2010 and 2013: "sprain or strain, including torn ligaments and muscles”), we did not observe any meaningful differences in proportions across survey years because of these changes (data not shown).

Figure 6 shows the proportion of fallrelated injuries by type of activity associated with the fall using combined data from the 2009/2010 and 2013 samples (the 2005 sample was excluded due to differences in the categorization of activity types). The largest proportions of fallrelated injuries resulted from slipping, tripping, stumbling or loss of balance while walking on a surface other than snow or ice $(45 \%)$, while walking on snow or ice $(16 \%)$ and while going up or down stairs or steps $(12 \%)$. Others reported falling due to health problems (e.g. fainting, weakness, dizziness, hip/knee giving out, seizure) $(7 \%)$, from furniture or while rising from furniture (e.g. bed, chair) (6\%), while engaged in sport or physical exercise (5\%) or from an elevated position (4\%).

Of those seniors with a fall-related injury in the 2005 sample, 133958 (69\%) reported seeking medical attention from a health professional in the 48 hours following the injury. This number increased to 163571 in 2009/2010 and 198164 in 2013, although the proportions were slightly lower $(64 \%$ in $2009 / 2010$ and $66 \%$ in 2013). Based on combined data from the three survey years, the majority of those seeking treatment for a 
FIGURE 4

Proportion of fall-related injuries by type of injury, $\geq 65$ years, Canada, CCHS 2005, 2009/2010, 2013

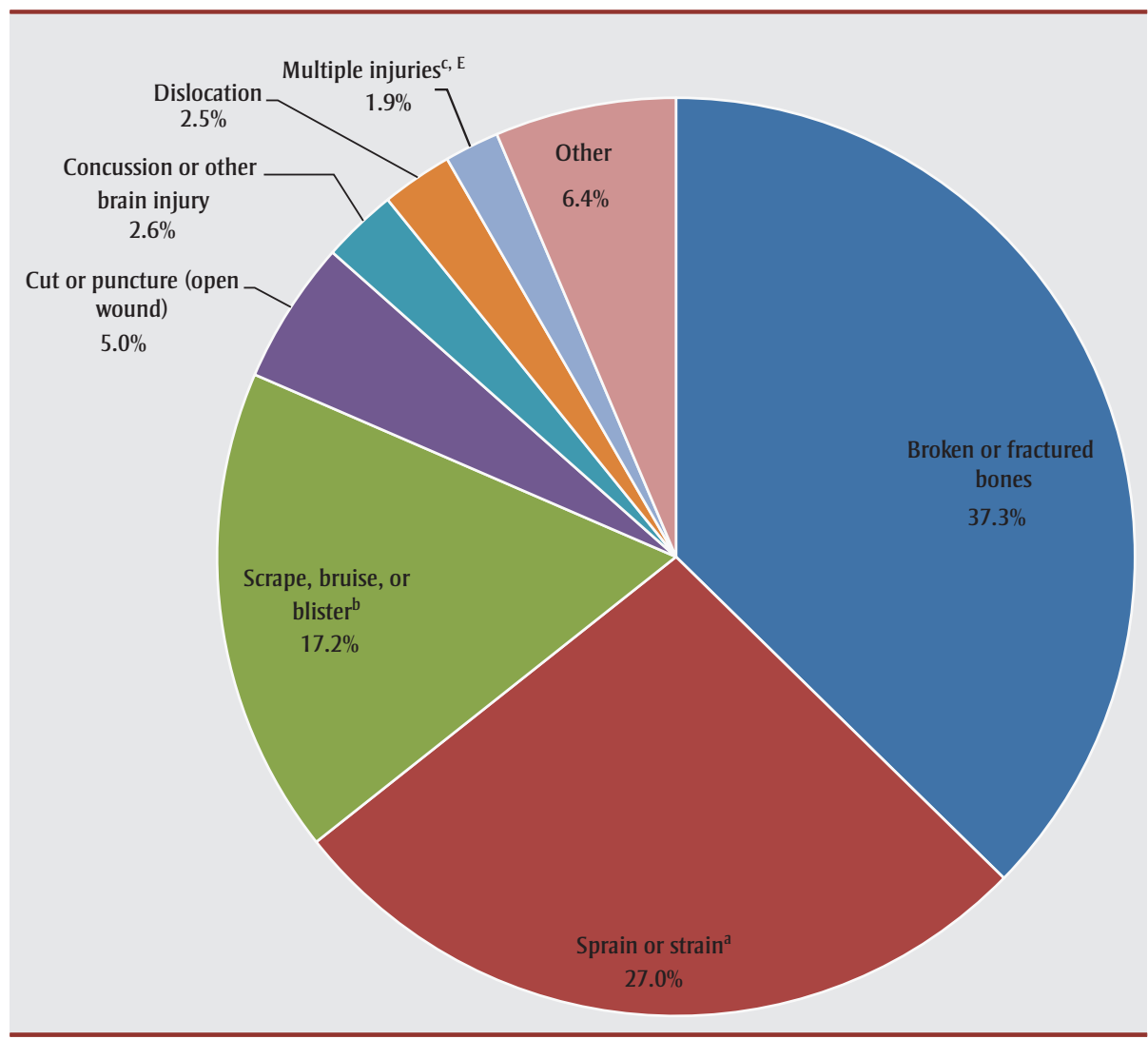

Source: Canadian Community Health Survey (2005, 2009/2010 and 2013 combined), Statistics Canada. Abbreviation: CCHS, Canadian Community Health Survey.

Note: There were slight wording changes for some categories in the 2009/2010 and 2013 questionnaires compared to 2005 (see below), but no meaningful differences were observed in the proportions of these categories across survey years.

a Stated as "sprain or strain" in 2005 and "sprain or strain (including torn ligaments and muscles)" in 2009/2010 and 2013.

b Stated as "scrape, bruise, blister" in 2005 and "scrape(s), bruise(s), blister(s) (including multiple minor injuries)" in 2009/ 2010 and 2013.

" Stated as "multiple injuries" in 2005 and "multiple serious injuries (excluding multiple minor injuries)" in 2009/2010 and 2013.

${ }^{\mathrm{E}}$ Estimate is associated with high sampling variability (i.e. coefficient of variation is between $16.6 \%$ and $33.3 \%$ ) - interpret with caution.

fall-related injury visited a hospital emergency department (71\%), a doctor's office $(15 \%)$, a clinic $(6 \%)$ and a hospital outpatient clinic (5\%). Less than $5 \%$ reported seeking medical treatment at a community health centre or at the site where the injury occurred. In addition, more than one-quarter of those who reported a medically attended fall-related injury were hospitalized overnight. Similar patterns were observed across all survey years (data not shown).

\section{Discussion}

Using population-based data from the 2005, 2009/2010 and 2013 CCHS, we provide an updated national profile of injuries resulting from falls among Canadians aged 65 years or older and examine trends over time.

From 2005 to 2013, the number of Canadian seniors who sustained a fall-related injury increased by over $50 \%$, which corresponds to the demographic shift towards an older population. ${ }^{21}$ Moreover, the increase in fallrelated injury rates is consistent with that reported for the period 2003 to 2009/2010 in Canada $^{7}$ as well as with trends observed in the United States, ${ }^{29,30}$ the Netherlands ${ }^{31}$ and Australia. $^{32,33}$ Of note, while the majority of these studies were restricted to injuries treated in emergency departments or that required hospitalization, our study shows time trends of self-reported fall-related injuries regardless of whether medical treatment was sought.

As with other studies, ${ }^{29-36}$ we found significantly higher rates of fall-related injuries among older women compared to older men across all survey years. Loss of bone mineral density following menopause may predispose women to a higher risk of fracture. ${ }^{37-39}$ The gender disparity in fall-related injury rates may also reflect differences between men and women in the strength of their lower extremities, chronic health conditions and lifestyle or behavioural factors. ${ }^{40}$

A study that used data from the CCHS Healthy Aging survey showed that men and women have different sets of socio-demographic, lifestyle/behavioural and medical risk factors for falls. ${ }^{41}$ For example, being widowed, separated or divorced, having a higher level of education and having an eye disorder were associated with elevated risk of falls in men, whereas older age, lower income, alcohol consumption, medication use and having diabetes, osteoporosis or a higher number of comorbid conditions increased the risk of falls in women. ${ }^{41}$ Note that although women are at higher risk for falls and fall-related injuries, mortality rates from falls are higher among men, ${ }^{7,42,43}$ who may be more severely injured due to the circumstances or events of their fall. ${ }^{35}$

While the rate of fall-related injuries increased steadily for women over time, we observed a peak among men in 2009/ 2010, followed by a small but non-significant decline in the most recent year, which may have partially accounted for the levelling off of the overall rate. This differs from the trends observed between 2003 and 2009/2010, during which there was a consistent increase in rates in both sexes. ${ }^{7}$

Although making direct comparisons is difficult due to differences in data sources and time periods examined, studies in other countries have shown either similar upward trends for both sexes ${ }^{29,30}$ or a sharper increase in men than in women. ${ }^{31-33}$ The reasons for the recent decline (or levelling off) that we observed among men are unclear and may be associated with changes in risk-taking behaviour and risk perception (e.g. taking extra caution when climbing 
FIGURE 5

Proportion of fall-related injuries by part of body injured, $\geq 65$ years, Canada, CCHS 2005, 2009/2010, 2013

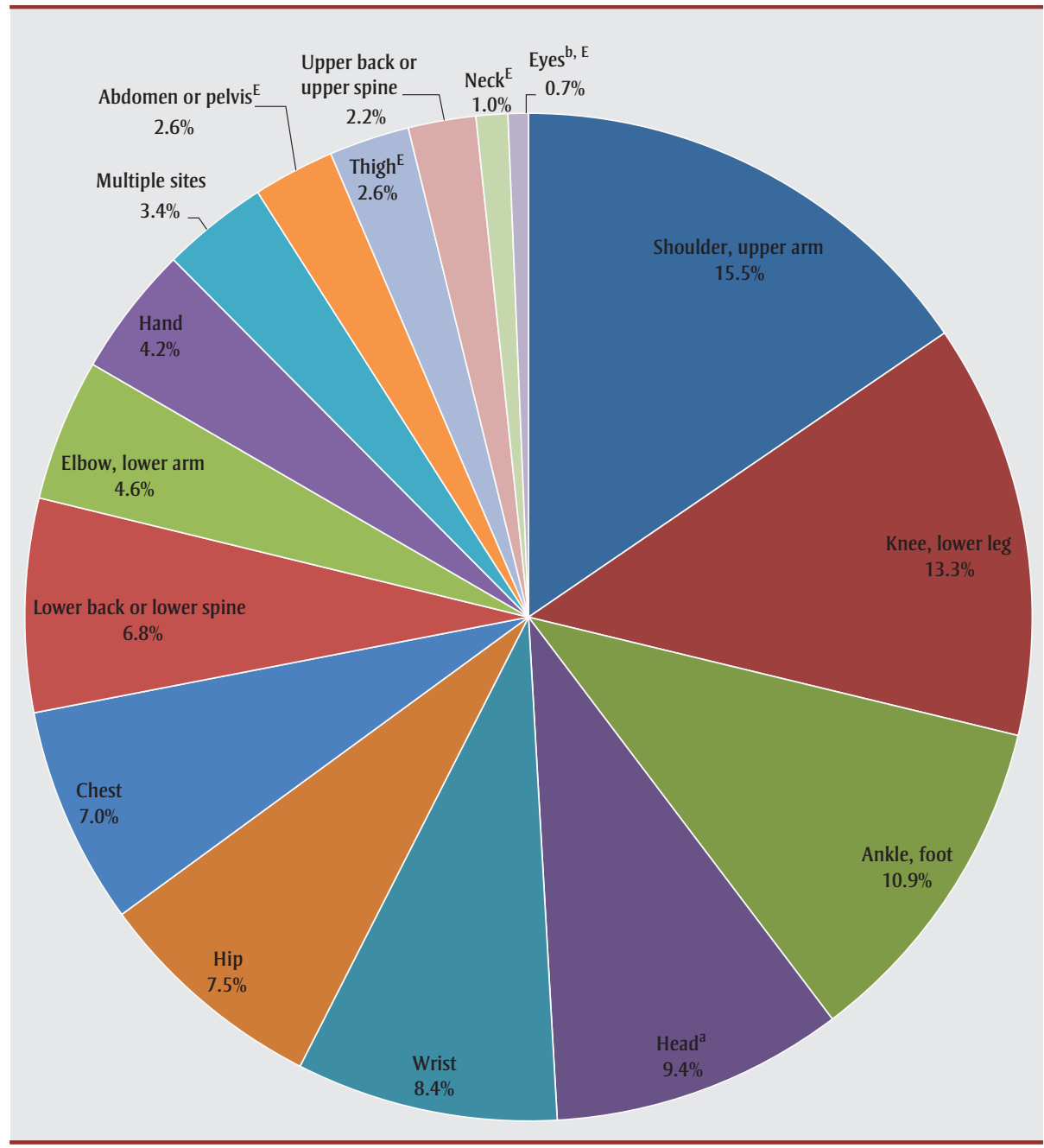

Source: Canadian Community Health Survey (2005, 2009/2010 and 2013 combined), Statistics Canada.

Abbreviation: CCHS, Canadian Community Health Survey.

Note: Wording for some categories in the 2009/2010 and 2013 questionnaires changed from 2005 (see below), but no meaningful differences were observed in the proportions of these categories across survey years.

a Stated as "head (excluding eyes)" in 2005 and "head (including facial bones)" in 2009/2010 and 2013.

b Stated as "eyes" in 2005 and "eyes (excluding fracture of facial bones around the eye)" in 2009/2010 and 2013.

${ }^{\mathrm{E}}$ Estimate is associated with high sampling variability (i.e. coefficient of variation is between $16.6 \%$ and $33.3 \%$ ) interpret with caution.

ladders and paying greater attention to surroundings while walking). ${ }^{6,7,44}$ However, more years of data are needed to assess longer-term trends and to determine whether fall-related injury rates are truly decreasing for older men in Canada.

The increase in fall risk with age is welldocumented $^{29-31,34-36}$ and can be attributed to age-induced declines in physical, sensory and cognitive function, as well as increases in comorbidities. ${ }^{43,45}$ Moreover, our results indicate that, although older seniors (i.e. $\geq 85$ years) continue to

experience higher rates of fall-related injuries compared to younger seniors, the gap between the younger and the older age groups appears to be a closing over time. A possible explanation is that younger seniors have been leading more more time pursuing activities that could increase their chances of falling. ${ }^{29,46}$ risk factors, including age-related shifts in lifestyle and behaviour, health conditions and medication use. ${ }^{47}$ In addition, recent declines in fall-related injury rates have also been reported in the older senior population ( $\geq 80$ years) in Finland ${ }^{48}$ and may reflect improvements in the functional ability and living environments of older seniors, although further assessment of trends is warranted. In contrast, studies in the $\mathrm{USA}^{30}$ and Australia ${ }^{33}$ have reported notably sharper increases in rates among older rather than younger age groups.

Our finding that fractures account for the greatest proportion of fall-related injuries is consistent with studies examining hospitalized $^{31,32}$ or emergency departmenttreated $^{35}$ fall-related injuries. It also suggests the importance of bone health in preventing fall-related fractures among seniors, especially given the high prevalence of osteoporosis in older women. ${ }^{7,49}$ In addition, the circumstances surrounding fall-related injuries among seniors are similar to those reported in the USA, ${ }^{36}$ as the majority involved slipping, tripping, stumbling or loss of balance while walking. However, of concern is the relatively large proportion of fall-related injuries among seniors that resulted from walking on ice or snow, highlighting the role of weather conditions in contributing to fall risk in Canada. ${ }^{7,50}$ Our results also demonstrate the burden of fall-related injuries on the health care system. Specifically, over two-thirds of Canadian seniors who sustained fall-related injuries sought medical treatment, most commonly at a hospital emergency department. With an aging population, health care utilization resulting from fall-related injuries and associated costs are expected to increase substantially over the next decades. active lifestyles than in the past, spending However, the trends we observed most likely involved a complex interplay of fall

\section{Strengths and limitations}

To our knowledge, this is the first peerreviewed study that examines trends of self-reported fall-related injuries among Canadian seniors over time.

A major strength of this study is our use of a well-validated population-based survey, which provided a national picture of fallrelated injuries representative of the entire community-dwelling senior population in Canada. Instead of restricting observations 
FIGURE 6

Proportion of fall-related injuries by type of activity, $\geq 65$ years, Canada, CCHS 2009/2010, 2013

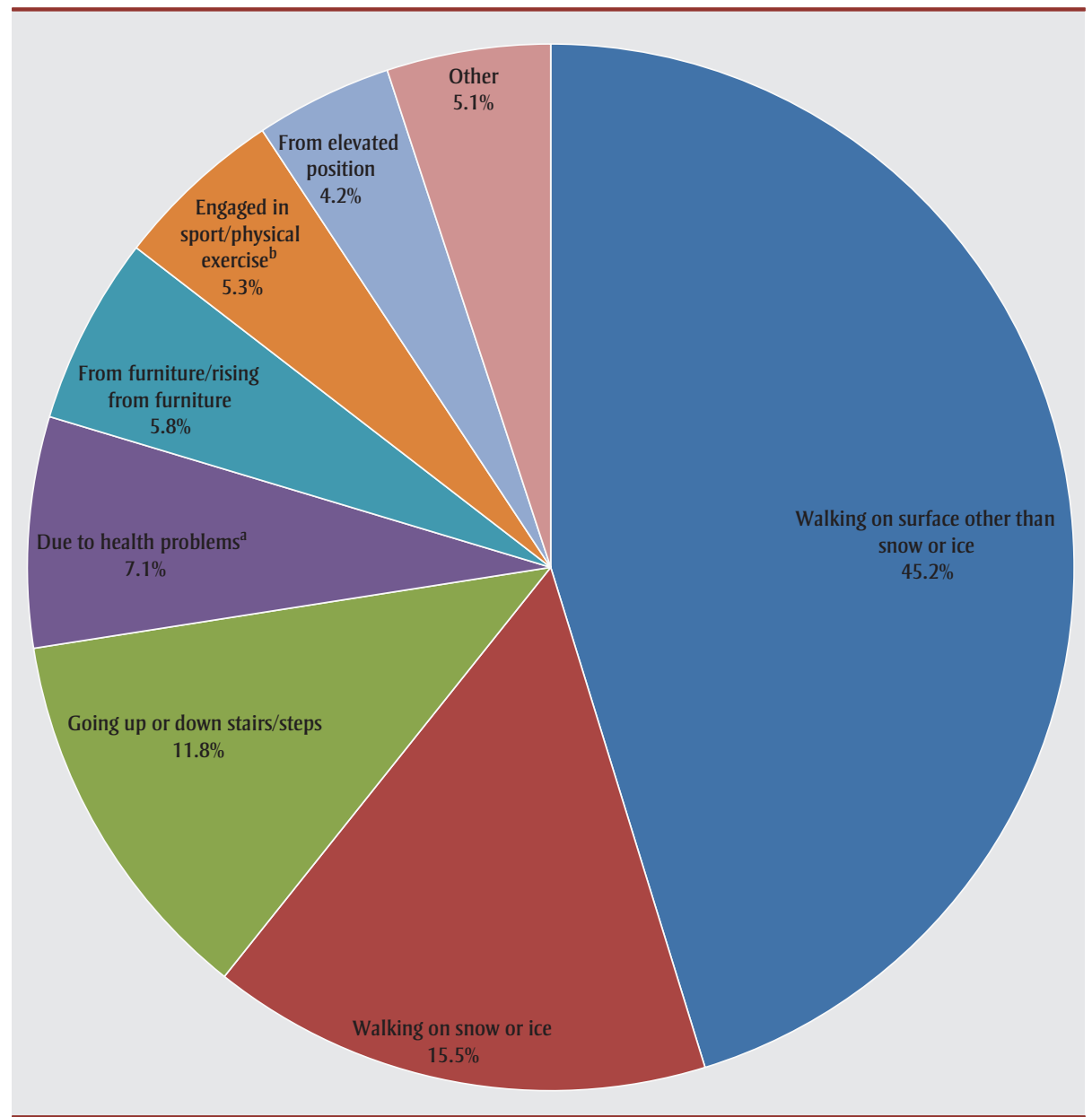

Source: Canadian Community Health Survey (2009/2010 and 2013 combined), Statistics Canada.

Abbreviation: CCHS, Canadian Community Health Survey.

Note: Data from the 2005 CCHS sample were not included in the analysis due to differences in the categorization of activity types compared to the 2009/2010 and 2013 surveys.

${ }^{a}$ Examples include fainting, weakness, dizziness, hip/knee giving out and seizure.

b Includes skating, skiing and snowboarding.

only to injuries involving hospitalization or emergency department visits, our study shows estimates and trends for a wider spectrum of fall-related injuries.

Our study also has several limitations that should be taken into consideration when interpreting the findings. First, based on the way the questions were designed in the CCHS, data were only collected for the most serious injury experienced by the respondent during the previous year. In other words, falls resulting in less serious injuries compared to other causes of injuries (e.g. traffic collisions) occurring in the same time period would not have been captured, likely leading to underestimated numbers and rates of fall-related injuries. Similarly, the survey did not collect information on multiple falls experienced by the same individual.

Second, since the CCHS does not collect data annually on injuries from all provinces and territories of Canada, our examination of national trends is limited to only several data points (i.e. 2005, 2009/2010 and 2013). As a result, potential changes in trends during the gap periods may have been missed. Nevertheless, we demonstrated a generally increasing trend of fall-related injuries consistent with that reported previously. ${ }^{7}$
Third, due to the self-reported nature of the CCHS, our results may be subject to measurement bias and misclassification. For example, questions about injuries may be interpreted differently by different respondents. There may also be the issue of underreporting of falls due to social desirability bias (i.e. an unwillingness to admit falling) or difficulty recalling, particularly among an older population. ${ }^{51}$

Fourth, low response rates, particularly in the most recent survey year (i.e. $66.8 \%$ in 2013), could have resulted in limited generalizability of study findings. However, to minimize potential bias associated with total non-response (i.e. refusal to participate or inability to contact the selected household or individual), Statistics Canada has adjusted the survey weights by redistributing weights of non-responding households or people to responding households or people with similar characteristics (e.g. geographic information, collection period, time and number of contact attempts). ${ }^{24}$

Finally, our findings may only be generalized to a relatively healthy population of seniors living in the community and do not apply to residents of care facilities, who may have a distinct risk profile for falls and very different circumstances and outcomes of fall-related injuries compared to the general population. ${ }^{52}$

\section{Conclusion}

As in other developed nations, fall-related injuries among seniors in Canada have been increasing over the past decade. Recent data also suggest differences in trends by sex and age, with a sharper increase among women and among younger seniors. As our population is rapidly aging, it remains essential to monitor trends and patterns of fall-related injuries along with the associated burdens on the health care system.

\section{References}

1. Tinetti ME, Speechley M, Ginter SF. Risk factors for falls among elderly persons living in the community. $\mathrm{N}$ Engl $\mathrm{J}$ Med. 1988;319(26):1701-7. 
2. O’Loughlin JL, Robitaille Y, Boivin JF, Suissa S. Incidence of and risk factors for falls and injurious falls among the community-dwelling elderly. Am J Epidemiol. 1993;137(3):342-54.

3. Tromp AM, Plujim SM, Smit JH, Deeg DJ, Bouter LM, Lips P. Fall-risk screening test: a prospective study on predictors for falls in community-dwelling elderly. J Clin Epidemiol. 2001;54(8):837-44.

4. Gill T, Taylor AW, Pengelly A. A populationbased survey of factors relating to the prevalence of falls in older people. Gerontology. 2005;51(5):340-5.

5. Morrison A, Fan T, Sen SS, Weisenfluh L. Epidemiology of falls and osteoporotic fractures: a systematic review. Clinicoecon Outcomes Res. 2013;5:9-18.

6. Pearson C, St-Arnaud J, Geran L. Understanding seniors' risk of falling and their perception of risk. Health at a Glance, October 2014. Ottawa (ON): Statistics Canada; 2014. [Statistics Canada, Catalogue No.: 82-624-X].

7. Public Health Agency of Canada. Seniors' falls in Canada: second report. Ottawa $(\mathrm{ON})$ : Public Health Agency of Canada; 2014.

8. Gill TM, Murphy TE, Gahbauer EA, Allore HG. Association of injurious falls with disability outcomes and nursing home admissions in community-living older persons. Am J Epidemiol. 2013;178(3):418-25.

9. Todd C, Skelton D. What are the main risk factors for falls among older people and what are the most effective interventions to prevent these falls? Health Evidence Network Report. Copenhagen (DM): World Health Organization Regional Office for Europe; 2004.

10. Wolinsky FD, Bentler SE, Liu L, et al. Recent hospitalization and the risk of hip fracture among older Americans. J Gerontol A Biol Sci Med Sci. 2009;64(2):249-55.

11. Ioannidis G, Papaioannou A, Hopman WM, et al. Relation between fractures and mortality: results from the Canadian Multicentre Osteoporosis Study. CMAJ. 2009;181(5):265-71.

12. Stel VS, Smit JH, Pluijm SM, Lips P. Consequences of falling in older men and women and risk factors for health service use and functional decline. Age Ageing. 2004;33(1):58-65.
13. Scott V, Pearce M, Pengelly C. Technical report: injury resulting from falls among Canadians age 65 and over on the analysis of data from the Canadian Community Health Survey, Cycle 2.1. in: Report on seniors' falls in Canada (2005). Ottawa (ON): Public Health Agency of Canada; 2005.

14. Tinetti ME, Kumar C. The patient who falls: "it's always a trade-off". JAMA. 2010;303 (3):258-66.

15. Scuffham P, Chaplin S, Legood R. Incidence and costs of unintentional falls in older people in the United Kingdom. J Epidemiol Community Health. 2003;57(9):740-4.

16. Stevens JA, Corso PS, Finkelstein EA, Miller TR. The costs of fatal and non-fatal falls among older adults. Inj Prev. 2006;12 (5):290-5.

17. Watson WL, Clapperton AJ, Mitchell RJ. The cost of fall-related injuries among older people in NSW, 2006-07. N S W Public Health Bull. 2011;22(3-4):55-9.

18. Hartholt KA, Polinder S, van der Cammen TJ, et al. Costs of falls in an ageing population: a nationwide study from the Netherlands (2007-2009). 2012. 43 (7) $1199-203$

19. SMARTRISK. The economic burden of injury in Canada. Toronto (ON): SMARTRISK; 2009.

20. Statistics Canada. The Canadian population in 2011: age and sex. Ottawa (ON): Statistics Canada; 2012. [Statistics Canada, Catalogue No.: 98-311-X2011001].

21. Statistics Canada. Population projections for Canada, provinces and territories, 2009 to 2036. Ottawa (ON): Statistics Canada; 2010. [Statistics Canada, Catalogue No.: 91-520-X].

22. Statistics Canada. Canadian Community Health Survey (CCHS) Cycle 3.1 (2005) public use microdata file (PUMF) User Guide. Ottawa (ON): Statistics Canada; 2006.

23. Statistics Canada. Canadian Community Health Survey (CCHS) Annual Component User Guide, 2010 and 2009-2010 microdata files. Ottawa (ON): Statistics Canada; 2011.

24. Statistics Canada. Canadian Community Health Survey (CCHS) Annual Component User Guide, 2013 microdata files. Ottawa (ON): Statistics Canada; 2014.
25. Yeung CW, Thomas S. Income imputation for the Canadian Community Health Survey. Working Paper (Methodology Branch). Ottawa (ON): Statistics Canada; 2013. [Statistics Canada, Catalogue No.: 11-619E no. 2013-003].

26. Rao JN, Scott AJ. On chi-squared tests for multiway contingency tables with cell proportions estimated from survey data. Ann Statist. 1984;12(1):46-60.

27. Thomas S, Wannell B. Combining cycles of the Canadian Community Health Survey. Health Rep. 2009;20(1):53-8.

28. Statistics Canada. BOOTVAR User Guide (BOOTVAR 3.2 - SAS version). Ottawa (ON): Statistics Canada; 2010.

29. Hartholt KA, Stevens JA, Polinder S, van der Cammen TJ, Patka P. Increase in fall-related hospitalizations in the United States, 20012008. J Trauma. 2011;71(1):255-8.

30. Orces $\mathrm{CH}$, Alamgir $\mathrm{H}$. Trends in fall-related injuries among older adults treated in emergency departments in the USA. Inj Prev. 2014;20(6):421-3.

31. Hartholt KA, van der Velde N, Looman CW, et al. Trends in fall-related hospital admissions in older persons in the Netherlands. Arch Intern Med. 2010;170(10):905-11.

32. Watson WL, Mitchell R. Conflicting trends in fall-related injury hospitalisations among older people: variations by injury type. Osteoporos Int. 2011;22(10):2623-31.

33. Bradley C. Trends in hospitalisations due to falls by older people, Australia 1999-00 to 2010-11. Injury research and statistics series no. 84. Canberra (AU): Australian Institute of Health and Welfare; 2013. [AIHW, Catalogue No.: INJCAT 160].

34. Peel NM, Kassulke DJ, McClure RJ. Population based study of hospitalised fall related injuries in older people. Inj Prev. 2002; $8(4): 280-3$.

35. Stevens JA, Sogolow ED. Gender differences for non-fatal unintentional fall related injuries among older adults. Inj Prev. 2005;11(2):115-9.

36. Schiller JS, Kramarow EA, Dey AN. Fall injury episodes among noninstitutionalized older adults: United States, 2001-2003. Advance data from vital and health statistics; no. 392. Hyattsville (MD): National Center for Health Statistics; 2007. [DHHS publication no. (PHS) 2007-1250]. 
37. Siris ES, Miller PD, Barrett-Connor E, et al. Identification and fracture outcomes of undiagnosed low bone mineral density in postmenopausal women: results from the National Osteoporosis Risk Assessment. JAMA. 2001;286(22):2815-22.

38. Stone KL, Seeley DG, Lui LY, et al. BMD at multiple sites and risk of fracture of multiple types: long-term results from the Study of Osteoporotic Fractures. J Bone Miner Res. 2003;18(11):1947-54.

39. Cranney A, Jamal SA, Tsang JF, Josse RG, Leslie WD. Low bone mineral density and fracture burden in postmenopausal women. CMAJ. 2007;177(6):575-80.

40. Duckham RL, Procter-Gray E, Hannan MT, Leveille SG, Lipsitz LA, Li W. Sex differences in circumstances and consequences of outdoor and indoor falls in older adults in the MOBILIZE Boston cohort study. BMC Geriatr. 2013;13:133.

41. Chang VC, Do MT. Risk factors for falls among seniors: implications of gender. Am J Epidemiol. 2015;181(7):521-31.

42. Stevens JA, Ryan G, Kresnow M. Fatalities and injuries from falls among older adults United States, 1993-2003 and 2001-2005. MMWR. 2006;55(45):1221-4.

43. World Health Organization. WHO global report on falls prevention in older age. Geneva $(\mathrm{CH})$ : World Health Organization; 2007. Available from: http://www.who.int/ ageing/projects/falls_prevention_older_ age/en/\#

44. Yuen HK, Carter RE. A measure of fall risk behaviors and perceptions among community-dwelling older adults. J Allied Health. 2006;35(4):e276-97.

45. Ambrose AF, Paul G, Hausdorff JM. Risk factors for falls among older adults: a review of the literature. Maturitas. 2013;75(1):51-61.

46. Victorino CC, Gauthier AH. Are Canadian seniors becoming more active? Empirical evidence based on time-use data. Can J Aging. 2005;24(1):45-56.

47. Deandrea S, Lucenteforte E, Bravi F, Foschi R, La Vecchia C, Negri E. Risk factors for falls in community-dwelling older people: a systematic review and meta-analysis. Epidemiology. 2010;21(5):658-68.
48. Korhonen N, Niemi S, Palvanen M, Parkkari J, Sievänen H, Kannus P. Declining age-adjusted incidence of fall-induced injuries among elderly Finns. Age Ageing. 2012;41(1):75-9.

49. Cummings-Vaughn LA, Gammack JK. Falls, osteoporosis, and hip fractures. Med Clin North Am. 2011;95(3):495-506.

50. Gao C, Abeysekera J. A systems perspective of slip and fall accidents on icy and snowy surfaces. Ergonomics. 2004;47(5):573-98.

51. Cummings SR, Nevitt MC, Kidd S. Forgetting falls. The limited accuracy of recall of falls in the elderly. J Am Geriatr Soc.1988; 36(7):613-6.

52. Deandrea S, Bravi F, Turati F, Lucenteforte E, La Vecchia C, Negri E. Risk factors for falls in older people in nursing homes and hospitals. A systematic review and metaanalysis. Arch Gerontol Geriatr. 2013;56(3): 407-15. 